Article

\title{
Dementia Literacy and Willingness to Dementia Screening
}

\author{
Yoko Aihara *(D) and Kiyoshi Maeda \\ Kobe Gakuin University, Kobe City 651-2180, Hyogo, Japan; maedak@reha.kobegakuin.ac.jp \\ * Correspondence: yanzu99@gmail.com
}

Received: 11 September 2020; Accepted: 30 October 2020; Published: 4 November 2020

check for updates

\begin{abstract}
The increasing prevalence of delayed and missed diagnoses for dementia constitutes major public concern. In this regard, inadequate knowledge and poor understanding of the condition may create a barrier to timely dementia screening. This cross-sectional study assessed dementia literacy, then identified the association between dementia literacy and willingness to undergo routine dementia screening among community-dwelling older adults in two urban areas of Japan. More specifically, structured questionnaires were distributed to a total of 854 individuals aged $\geq 65$ years. A multivariate logistic regression was then used to explore the factors associated with dementia literacy and willingness to undergo routine dementia screening. Results showed that younger respondents and respondents who received dementia information from television/radio and/or paper-based sources were more likely to have high dementia literacy. While less than half of participants were willing to undergo routine dementia screening, those with higher dementia literacy were more willing to do so (albeit, not a statistically significant difference). Although there are pros and cons to routine dementia screening, it is necessary to implement such a system to detect dementia and cognitive impairment. Further, assessments should also attempt to gain information about individual beliefs and understandings related to dementia information.
\end{abstract}

Keywords: dementia literacy; health literacy; information; screening; willingness

\section{Introduction}

A recent systematic review of the global burden of diseases reported that 43.1 million people are living with dementia worldwide, with the number more than doubling from 1990 to 2016 [1]. Although the magnitude of public issues related to dementia is increasing, other studies have revealed that approximately $62 \%$ of dementia cases are undetected [2]. Similarly, anywhere from one-half to two-thirds of early-stage dementia cases are likely missed during diagnosis [3]. In order to improve the lives of people with dementia and their caregivers while decreasing the community-wide impacts of the disease, the World Health Organization (WHO) announced the "global action plan on the public health response to dementia 2017-2025." One of the plan's most important strategies involves raising public awareness about dementia, thus fostering a more accurate understanding [4]. In this regard, adequate knowledge may reduce the stigmatization of people with dementia while also resulting in better early recognition practices.

Health literacy is defined as the range of cognitive and social skills that enable people to obtain, understand, and use information for the purpose of enhancing their health and well-being and engage in healthcare-related decision-making [5]. Health literacy also refers to one's knowledge, motivations, and competencies when accessing, understanding, appraising, and applying health information [6]. Individuals with lower health literacy are unable to adequately understand and access health information, which may lead to negative attitudes about cancer screening [7]. Several studies have also reported that older adults with lower health literacy tend to have poorer health outcomes, 
lower preventive service compliance, and higher healthcare utilization [8-10]. In this context, improved dementia literacy may increase early diagnosis of dementia and result in more timely support for people with dementia.

As mentioned above, there are both pros and cons to routine dementia screening. For example, the US Preventive Service Task Force concluded that there was a lacking of direct evidence for the benefits of early screening to detect cognitive impairments in older adults [11]. Dementia screening may also not be effective for healthy individuals due to issues stemming from both misdiagnosis and overdiagnosis, which can have significant long-term effects including stigmatization, the loss of employment and/or autonomy, economic problems, and additional burdens placed on health systems that do not have the capacity to respond to increased demands resulting from screening [12]. On the other hand, a national early dementia detection program may improve quality-adjusted life expectancy while also reducing the costs of screening for older persons [13]. Although interventions intended to cure dementia have been implemented, recent studies have also indicated that approximately one-third of dementia cases are likely preventable [14]. As the majority of people living with dementia remains undiagnosed, it is highly important to increase public awareness about the methods for identifying the diseases, thereby resulting in appropriate treatments and timely social support.

Japan has one of the highest rates of population aging in the world. In this context, current estimates indicate that more than 7 million people aged 65 years and older will have dementia by 2025, with the total costs of the disease expected to increase 1.6 times between 2014 and 2060 [15]. For those reasons, early dementia diagnosis has become part of a national dementia strategy. Several local governments have also initiated subsidized systems that offer free dementia screenings at hospitals and clinics. A previous study investigated the intention to use the subsidized system among community-dwelling older adults and found that while only $20 \%$ of participants knew about the system, $60 \%$ were willing to use free dementia screenings [16]. Following this evidence, we hypothesized that additional information and adequate knowledge about dementia would be associated with willingness to undergo dementia screening. Thus, this study aimed to assess dementia literacy, then identified the association between dementia literacy and willingness to undergo regular dementia screening among community-dwelling older adults in urban areas of Japan.

\section{Materials and Methods}

\subsection{Study Location and Study Participants}

This study was conducted in an area adjacent to the cities of Akashi and Kobe in Japan. Both initiated subsidized systems for dementia screening for older adults in 2019 fiscal year. In the same year, an initial survey was conducted among all community-dwelling persons aged 65 years and above who lived in this area (details are given elsewhere) [16]. Among the 2269 total respondents, 1165 agreed to participate in a follow-up survey. Self-administered questionnaires were thus distributed to each of these individuals, resulting in 854 response (rate of $73 \%$ ). The sample size was calculated using a formula for the interval estimation of the population proportion, in which the outcome variable was set as dementia literacy. We followed information from a previous study reporting that $55 \%$ of older adults living in urban China had adequate dementia literacy [17]. Using an expected sampling error of 0.05 , a confidence interval of 0.95 , and a potential proportion of adequate dementia literacy $=55 \%$, we deemed that a minimum sample of 381 was sufficient. The survey was conducted from November 2019 to March 2020.

\subsection{Variables}

The outcomes of the variables were set as dementia literacy and willingness to undergo regular dementia screening. The dementia literacy component was developed based on eight questions developed by Zhang et al. [17] specifically regarding the symptoms, prevalence, nature, and treatment methods for dementia. Prevalence and treatment options were modified to fit the Japanese context. 
Internal consistency reliability of the literacy questions was not high but acceptable (Cronbach's alpha coefficient $=0.57$ ). Willingness to undergo dementia screening was determined by asking participants whether they were willing to undergo regular (annual) dementia screening (answers were selected from options of "yes," "no," and "do not know"). Participants who indicated they were unwilling to engage in these screenings were also asked to select from the following reasons: "shameful to be diagnosed with dementia," "fear of being diagnosed with dementia," "there is no cure for the disease," "bothersome to visit the clinic," "economic burdens," "annoyance to family members," "do not know which doctor can be consulted," and others.

As relevant information sources are related to dementia literacy [18], participants were asked which sources they use to learn about the disease. This included options of television/radio, verbal information (family members and friends), paper-based information (books, magazine/newspaper, and local paper), professional information (medical staff and classes), and Internet. We then assessed intellectual activity levels by asking participants how often they chat with family members and/or friends (almost every day, 2-3 times per week, 1-2 times per month, or rarely) and how often they read newspapers/magazines/books (almost every day, sometimes, or rarely). Cognitive impairments and depressive symptoms are also associated with dementia literacy and willingness to undergo regular dementia screenings [17,19]. We, therefore, assessed cognitive impairments using the Dementia Assessment Sheet for Community-based Integrated Care System 21 items (DASC-21), which has been previously deemed sufficiently reliable and valid for detecting dementia [20]. Depressive symptoms were then assessed based on five items from the Geriatric Depression Scale (GDS-5) [21], the Japanese version of which has been previously deemed sufficiently valid [22]. Self-rated health status was determined based on 4-point Likert scale consisting of "very good," "good," "fairly poor," or "poor." We also asked respondents for basic demographic information, including items on age, gender, family structure, educational level, and whether they had primary care physicians.

\subsection{Analysis}

Descriptive statistics were applied to calculate the proportions and numbers of each variable. Each question on dementia literacy was scored as either correct (1 point) or incorrect/do not know ( 0 points) (total scores ranging from 0 to 8 points). The average dementia literacy score was 4.2 , thus categorized as "high dementia literacy" based on a threshold of $\geq 4$ points, with "low dementia literacy" being determined at scores $<4$ points. Willingness to undergo dementia screening was scored as either "yes" (1 point) or "no/do not know" (0 points). A chi-squared test was then conducted to identify the factors associated with dementia literacy and willingness to undergo regular dementia screenings while a multiple logistic regression model was applied to control for confounding factors. All statistical analyses were performed using the STATA 16.0 software (StataCorp., College Station, TX, USA) and statistical significance was set to $5 \%$.

\subsection{Ethics}

All participants received written explanations of the study protocol. We then obtained written, informed consent from those who agreed to participate. This study received ethical approval by the Ethics Committee of Kobe Gakuin University (protocol number Sourin-18-16, approved on 6 February 2019).

\section{Results}

\subsection{Factors Associated with Dementia Literacy}

The average participant age was 78.2 years (range of 65-100), with 53\% being female. Among all participants, $14 \%$ were assessed as possibly having dementia (DASC-21 $\geq 31$ ), while $28 \%$ had depressive symptoms (GDS-5 $\geq 2$ ). 
Only $1.7 \%$ of the respondents answered all dementia literacy questions correctly. The question with the highest rate of correct answers was that on memory loss from dementia $(88.2 \%)$, while the lowest rate was for the item on the prevalence of dementia in Japan (22.7\%) (Table 1). The majority of respondents obtained dementia-related information from television (75\%) and newspapers/magazines (52\%). On the other hand, $9 \%$ of the respondents answered that they did not receive any dementia-related information.

Table 1. Questions of dementia literacy.

\begin{tabular}{|c|c|c|}
\hline Questions & Answers & Correct Rate \\
\hline $\begin{array}{l}\text { Q1. In the following opinion, } \\
\text { which one do you NOT agree? }\end{array}$ & $\begin{array}{c}\text { 1-Dementia is a disease } \\
\text { 2-Dementia is not a disease, it is a normal aging process } \\
\text { 3-Dementia is common among older adults } \\
\text { 4-Dementia does not mean disease, but rather refers to a } \\
\text { variety of disease } \\
\text { 5-I do not know }\end{array}$ & $28.4 \%$ \\
\hline $\begin{array}{l}\text { Q2. Currently, among people aged } \\
\text { older } 65 \text { years, one in how many } \\
\text { persons are living with dementia? }\end{array}$ & $\begin{array}{l}\text { 1-One in two persons } \\
\text { 2-One in four persons } \\
\text { 3-One in five persons } \\
\text { 4-One in seven persons } \\
\text { 5-I do not know }\end{array}$ & $22.7 \%$ \\
\hline $\begin{array}{l}\text { Q3. In the following options, } \\
\text { which one is likely to be a } \\
\text { symptom of dementia? }\end{array}$ & $\begin{array}{l}\text { 1-Headache } \\
\text { 2-Faint } \\
\text { 3-Dizziness } \\
\text { 4-Bad memory } \\
\text { 5-I do not know }\end{array}$ & $88.2 \%$ \\
\hline $\begin{array}{l}\text { Q4. Which is the most common } \\
\text { difficulty would people with } \\
\text { dementia meet? }\end{array}$ & $\begin{array}{l}\text { 1-Learning difficulty } \\
\text { 2-Difficulty in work } \\
\text { 3-Difficulty in self-care } \\
\text { 4-All of above (all 1-3 options) } \\
\text { 5-I do not know }\end{array}$ & $43.5 \%$ \\
\hline $\begin{array}{l}\text { Q5. Which is the most common } \\
\text { symptom of dementia? }\end{array}$ & $\begin{array}{l}\text { 1-It is easier to forget the recent events than the past events } \\
\text { 2-It is easier to forget the past events than the recent events } \\
\text { 3-It is easy to forget both past events and recent events } \\
\text { 4-None of above } \\
\text { 5-I do not know }\end{array}$ & $61.5 \%$ \\
\hline $\begin{array}{l}\text { Q6. Which of the following is } \\
\text { NOT a symptom ofDementia? }\end{array}$ & $\begin{array}{c}\text { 1-Easy to get lost } \\
\text { 2-It cannot remember someone's name } \\
\text { 3-Often forget to return the things that they borrowed back } \\
\text { 4-Do not forget their own things } \\
\text { 5-I do not know }\end{array}$ & $58.8 \%$ \\
\hline $\begin{array}{l}\text { Q7. If you or your family members } \\
\text { get dementia, which doctor you } \\
\text { would not seek for help? }\end{array}$ & $\begin{array}{l}\text { 1-Neurosurgeon } \\
\text { 2-Neurologist } \\
\text { 3-Internist (General physician) } \\
\text { 4-Psychologist } \\
\text { 5-I do not know }\end{array}$ & $46.3 \%$ \\
\hline $\begin{array}{l}\text { Q8. In the following opinions } \\
\text { related to dementia, which one do } \\
\text { you agree? }\end{array}$ & $\begin{array}{l}\text { 1-Dementia is not a disease, treatment is not needed } \\
\text { 2-Although dementia is a disease, treatment is not necessary } \\
\text { 3-Dementia cannot be cured, treatment is not needed } \\
\text { 4-Dementia is a disease, treatment is needed } \\
\text { 5-I do now know }\end{array}$ & $71.8 \%$ \\
\hline
\end{tabular}

Note: Answers shown in bold are correct answer.

Table 2 shows the factors associated with dementia literacy. High literacy was associated with younger ages, higher educational levels, living with family members, using more dementia-related information sources, suspectable depression, and higher frequencies of chatting and reading.

A multivariate logistic regression showed that younger respondents and those who obtained dementia information from television/radio and/or paper-based sources were more likely to have high levels of dementia literacy (Table 3). 
Table 2. A chi-square test to identify factors associated with dementia literacy $(n=775)$.

\begin{tabular}{|c|c|c|c|}
\hline Variables & $\begin{array}{l}\text { High Literacy } \\
\quad(n=519)\end{array}$ & $\begin{array}{l}\text { Low Literacy } \\
\quad(n=256)\end{array}$ & $p$-Value \\
\hline \multicolumn{4}{|l|}{ Age } \\
\hline $65-74$ years & $189(80.1 \%)$ & $47(19.9 \%)$ & \multirow[t]{2}{*}{$<0.001$} \\
\hline $75+$ years & $330(61.2 \%)$ & $209(38.8 \%)$ & \\
\hline \multicolumn{4}{|l|}{ Gender } \\
\hline Male & $252(68.1 \%)$ & $118(31.9 \%)$ & \multirow[t]{2}{*}{0.52} \\
\hline Female & $267(65.9 \%)$ & $138(34.1 \%)$ & \\
\hline \multicolumn{4}{|l|}{ Educational level } \\
\hline Elementary school/junior high school & $78(56.1 \%)$ & $61(43.9 \%)$ & \multirow{4}{*}{0.005} \\
\hline High school & $230(69.1 \%)$ & $103(30.9 \%)$ & \\
\hline University/post-graduate school & $210(70.2 \%)$ & $89(29.8 \%)$ & \\
\hline Missing & $1(25.0 \%)$ & $3(75.0 \%)$ & \\
\hline \multicolumn{4}{|l|}{ Family structure } \\
\hline Living alone & $153(60.7 \%)$ & $99(39.3 \%)$ & \multirow{3}{*}{0.03} \\
\hline Living with family members & $278(69.9 \%)$ & $156(30.1 \%)$ & \\
\hline Missing & $4(80.0 \%)$ & $1(20.0 \%)$ & \\
\hline Average number of information sources & 2.79 & 2.12 & $<0.001$ \\
\hline \multicolumn{4}{|l|}{ Cognitive impairments } \\
\hline DASC $-21<31$ & $426(68.7 \%)$ & $194(31.3 \%)$ & \multirow{3}{*}{0.11} \\
\hline DASC- $21 \geq 31$ & $58(58.6 \%)$ & $41(41.4 \%)$ & \\
\hline Missing & $35(62.5 \%)$ & $21(37.5 \%)$ & \\
\hline \multicolumn{4}{|l|}{ Depressive symptoms } \\
\hline GDS- $5<2$ & $372(71.3 \%)$ & $150(28.7 \%)$ & \multirow{3}{*}{0.004} \\
\hline GDS- $5 \geq 2$ & $137(60.6 \%)$ & $89(39.4 \%)$ & \\
\hline Missing & $10(37.0 \%)$ & $17(63.0 \%)$ & \\
\hline \multicolumn{4}{|l|}{ Frequency of chat with family/friends } \\
\hline Almost everyday & $366(71.1 \%)$ & $149(28.9 \%)$ & \multirow{4}{*}{0.003} \\
\hline 2-3 times per week & $103(60.2 \%)$ & $68(39.8 \%)$ & \\
\hline $1-2$ times per month or less & $49(55.7 \%)$ & $39(44.3 \%)$ & \\
\hline Missing & $1(100 \%)$ & 0 & \\
\hline \multicolumn{4}{|l|}{ Frequency of reading } \\
\hline Almost everyday & $406(69.8 \%)$ & $176(30.2 \%)$ & \multirow{3}{*}{0.006} \\
\hline Sometimes & $73(62.4 \%)$ & $44(37.6 \%)$ & \\
\hline Rarely & $40(52.6 \%)$ & $36(47.4 \%)$ & \\
\hline
\end{tabular}

Table 3. Multivariate logistic regression model to identify factors associated with dementia literacy $(n=775)$.

\begin{tabular}{ccc}
\hline Variables & Odds Ratio & 95\% Confidence Interval \\
\hline Age (year) & 0.94 & $0.91,0.96$ \\
Gender & & \\
Male & Ref. & $0.60,1.25$ \\
Female & 0.87 & \\
Educational level & & $0.66,1.75$ \\
Elementary school/Junior high school & Ref. & $0.62,1.72$ \\
High school & 1.07 & \\
University/Post-graduate school & 1.03 & $0.96,2.08$ \\
Family structure & & $1.02,2.34$ \\
Living alone & Ref. & \\
Living with family members & 1.41 & \\
Dementia information sources & 1.54 & \\
Television/radio & & \\
\hline
\end{tabular}


Table 3. Cont.

\begin{tabular}{ccc}
\hline Variables & Odds Ratio & 95\% Confidence Interval \\
\hline Verbal information & 1.15 & $0.81,1.65$ \\
Internet & 1.98 & $0.99,4.00$ \\
Profession & 1.58 & $0.93,2.69$ \\
Paper-based & 1.56 & $1.07,2.29$ \\
Cognitive impairments & & \\
DASC-21 <31 & Ref. & $0.58,1.64$ \\
DASC-21 $\geq 31$ & 0.98 & \\
Depressive symptoms & & \\
GDS-5 $<2$ & Ref. & $0.53,1.18$ \\
GDS-5 $\geq 2$ & 0.79 & $0.86,1.46$ \\
Frequency of chat with family/friends & 1.12 & $0.81,1.96$ \\
Frequency of reading & 1.25 &
\end{tabular}

Willingness to undergo regular dementia screening and dementia literacy.

\subsection{Willingness to Undergo Regular Dementia Screening and Dementia Literacy}

Among all respondents, $41 \%$ were willing to undergo regular dementia screening, with more than half being unwilling or undecided. The main reasons for unwillingness were "bothersome to visit the clinic" (42\%) and "do not know which doctors can be consulted" (32\%) (Table 4).

Table 4. The reasons of unwilling to undergo regular dementia screening.

\begin{tabular}{cc}
\hline Reasons & $\%$ \\
\hline Shameful to be diagnosed with dementia & 4.5 \\
Fear of being diagnosed with dementia & 17 \\
There is no cure for the disease & 9.5 \\
Bothersome to visit clinic & 41.8 \\
Economic burdens & 9.9 \\
Annoyance to family members & 4.5 \\
Do not know which doctor can be consulted & 31.5 \\
Others & 26.2 \\
\hline
\end{tabular}

A univariate logistic regression model showed that respondents with higher dementia literacy were more likely to accept regular dementia screenings than those with low dementia literacy (odds ratio $(\mathrm{OR})=1.40,95 \%$ confidence interval $(\mathrm{CI})=1.02,1.92)$. However, there were no statistically significant differences after controlling for other variables $(\mathrm{OR}=1.36,95 \% \mathrm{CI}=0.94,1.93)$. Older adults with poor self-rated health were more likely to undergo regular dementia screening than those with better self-rated health $(\mathrm{OR}=0.64,95 \% \mathrm{CI}=0.42,0.97)$ (Table 5).

Table 5. Univariate and multivariate logistic regression for factors associated with undergoing regular dementia screenings $(n=807)$.

\begin{tabular}{ccc}
\hline Variables & Univariate Logistic & Multivariate Logistic \\
\cline { 2 - 3 } & OR (95\% CI) & OR (95\% CI) \\
\hline Age (year) & $1.01(0.99,1.03)$ & $1.01(0.98,1.03)$ \\
Gender & Ref. & Ref. \\
Male & $1.12(0.85,1.49)$ & $1.19(0.86,1.65)$ \\
Female & & Ref. \\
Educational level & Ref. & $1.46(0.90,2.36)$ \\
Elementary school/Junior high school & $1.56(1.03,2.34)$ & $1.49(0.91,2.43)$ \\
High school & $1.47(0.96,2.19)$ & Ref. \\
College/University & & \\
Family structure & Ref. & \\
Living alone & &
\end{tabular}


Table 5. Cont.

\begin{tabular}{|c|c|c|}
\hline \multirow{2}{*}{ Variables } & Univariate Logistic & Multivariate Logistic \\
\hline & OR $(95 \% \mathrm{CI})$ & OR $(95 \% \mathrm{CI})$ \\
\hline Living with family members & $0.78(0.58,1.05)$ & $0.72(0.51,1.03)$ \\
\hline \multicolumn{3}{|l|}{ Dementia literacy } \\
\hline Low & Ref. & Ref. \\
\hline High & $1.40(1.02,1.92)$ & $1.35(0.94,1.93)$ \\
\hline \multicolumn{3}{|l|}{ Cognitive impairment } \\
\hline DASC $-21<31$ & Ref. & Ref. \\
\hline DASC- $21 \geq 31$ & $1.10(0.72,1.67)$ & $1.12(0.68,1.84)$ \\
\hline \multicolumn{3}{|l|}{ Depressive symptoms } \\
\hline GDS- $5<2$ & Ref. & Ref. \\
\hline GDS $-5 \geq 2$ & $0.94(0.68,1.29)$ & $0.81(0.54,1.20)$ \\
\hline \multicolumn{3}{|l|}{ Having primary care physicians } \\
\hline No & Ref. & Ref. \\
\hline Yes & $1.32(0.81,2.14)$ & $1.37(0.78,2.39)$ \\
\hline \multicolumn{3}{|l|}{ Self-rated health } \\
\hline Fairy poor/poor & Ref. & Ref. \\
\hline Very good/good & $0.76(0.54,1.06)$ & $0.64(0.42,0.98)$ \\
\hline
\end{tabular}

OR $=$ odds ratio, $95 \% \mathrm{CI}=95 \%$ confidence interval.

\section{Discussion}

This study assessed dementia literacy and willingness to undergo regular dementia screenings among community-dwelling older adults. Results showed that respondents of younger ages had higher dementia literacy after controlling for educational level, depression, and cognitive impairment. A systematic review reports that older age was strongly associated with limited health literacy [23], while another study suggested that age-related changes in cognitive function that are not captured by dementia screening may affect health literacy levels among the older adults [24]. Decline in hearing and vision functions with aging may also be related to limited dementia literacy. As dementia is strongly associated with advanced age, it is especially important to improve dementia literacy among older populations. In this regard, educational interventions may help with dementia management as older persons with limited health literacy tend to perceive more barriers to communication [25]. Active learning education has been proven effective for improving health literacy and health behaviors [26] and use of simple language and visual elements (e.g., pictures and photos) has been supported.

In this study, we found that the majority of participants gathered dementia-related information from a variety of sources, and diversity of sources was significantly associated with higher dementia literacy. Among the variety of sources, respondents who obtained dementia information from television/radio and/or paper-based sources had higher overall levels of dementia literacy than those who did not. Similar findings were reported by a previous study targeting older adults in Vietnam, which showed that television and Internet usage were associated with higher health literacy [27]. An empirical study showed that the use of paper-based nutritional information was associated with higher nutrition literacy among older people [28]. Television and radio are easy media to access information for older people. The global action plan for dementia recommends collaboration between the media and relevant stakeholders during awareness campaigns. In this context, dementia-related information is broadcasted frequently to raise public awareness about dementia in Japan. A qualitative study found that participants with adequate functional health literacy identified a variety of information sources [29], while exposure to dementia-related information from multiple sources were associated with greater dementia knowledge [30]. In sum, dementia literacy can substantially be increased through use of multiple information sources. 
Our initial survey found that $60 \%$ of community-dwelling older adults intended to undergo dementia screenings using the subsidized system for dementia diagnosis [16]. Although it may be assumed that free dementia screenings are attractive for older people, this follow-up survey revealed that less than half of respondents wished to undergo regular dementia screenings. Similar to this study's findings, $49 \%$ of older adults living in retirement communities in the U.S. stated that they would agree to routine screening for memory problems [31]. Many participants said they did not wish to undergo routine dementia screenings due to the burdens associated with clinic visitation and/or not knowing which physicians can be consulted. It is also known that early-stage dementia and mild cognitive impairments are not risk factor for life. Given these conditions, many people may not believe it is important to diagnose early dementia. A previous study conducted in Australia reported that many participants were optimistic about the prognosis for dementia and that more than half of the respondents did not worry about getting dementia, while $85 \%$ of them answered they would not recognize the early symptoms of Alzheimer disease [32]. This study also showed that low correct response rates were found for items on the nature $(28.4 \%)$ and prevalence of dementia $(22.7 \%)$. This may be because many older adults are interested in knowing how to prevent dementia, but there is relatively little interest in early recognition of symptoms. However, a systematic review reported that attitudes toward undergoing dementia screening were diverse and fragmented [33]. A qualitative study conducted in the UK found that acceptance of dementia screening depended on a variety of reasons [34]. To promote screening acceptance, further research needs to explore the reasons for acceptance or refusal to undergo routine dementia screening.

This study showed that higher dementia literacy was marginally associated with an increased preference for regular dementia screening. A previous literature review reported that low levels of awareness about screening led to misunderstandings about both the reason for dementia tests and the implication of test results [33]. Another study similarly found that individuals with low health literacy were less likely to retain cancer screening information [35], with other research indicating that low health literacy may constitute a barrier to regular screening participation [36]. Although this study did not find a statistically significant association between dementia literacy and the willingness to undergo dementia screening, raising public awareness and provision of screening information are part of the key strategies for promoting accessibility of dementia screening.

Further, participants with poor self-rated health status were more willing to undergo regular dementia screenings than those with better self-rated health status. A study involving older adults in the USA also found that unhealthy individuals were more willing to undergo routine dementia screenings [31], while another qualitative study reported that persons' existing health state and perceived susceptibility to illness may impact the acceptability of dementia screenings [37]. Along with this study's results, it thus appears that older adults with poor health status may have increased concerns about the need for long-term care than healthy individuals, which likely influences their decision to undergo routine dementia screenings. Although there is currently insufficient evidence about the effectiveness of routine dementia screening [11], multiple benefits and comparatively few/minor harms are associated with specific screening tests for dementia [38]. Increasing participation of healthy individuals in dementia screening and provision of information regarding benefits of timely diagnosis of dementia are needed.

This study also had limitations. First, respondents agreed to participate in the follow-up survey after receiving information on the study purpose. In this regard, these may have generally been more interested in dementia and were, thus, more active in collecting dementia information. Sampling bias may have, therefore, led to an overestimation of dementia literacy. Second, content validity of the instrument for measuring dementia literacy was not high (Cronbach's alpha=0.57). Various instruments and aspects of dementia literacy have been used for dementia research [39]; thus, further research needs to accurately measure dementia literacy to better understand association between literacy and dementia. Missing data were excluded in multiple regression analyses because the numbers of incomplete data were less than $10 \%$ and the results of the analyses may not be biased [40]. However, 
if the amounts of missing values are large, we need to handle missing values for reducing bias in terms of estimation of parameters of interests [40]. Moreover, we only assessed willingness to undergo regular screenings and did not assess actual behavior in this regard. Further study is needed to identify the association between dementia literacy and participation in dementia screening.

\section{Conclusions}

More than half of this study's participants were unwilling to undergo routine dementia screenings, with many referring to the burdens associated with clinic visitation and the lack of sufficient information about screening. It is, therefore, important to increase access to adequate dementia information, which should raise general awareness about dementia and, thus, improve timely diagnosis of dementia. Further, sources such as television/radio and/or paper-based information may be effective for improving dementia literacy, which influences decisions to undergo dementia screening and receive advance care. Although there are pros and cons to routine dementia screening, a system of detecting dementia and cognitive impairment should be implemented to better understand individual beliefs and understandings related to the disease. Further research also needs to clarify which interventions are effective in increasing dementia literacy as well as changing perspectives on undergoing dementia screening among community-dwelling older adults.

Author Contributions: Conceptualization, methodology, formal analysis, investigation, and writing-original draft preparation, Y.A.; and supervision, K.M. All authors have read and agreed to the published version of the manuscript.

Funding: This research received no external funding.

Acknowledgments: We thank all participants and Noriko Fukui who helped with data collection and data input.

Conflicts of Interest: The authors declare that they have no conflict of interest. The funders had no role in the design of the study; in the collection, analyses, or interpretation of the data; in the writing of the manuscript; or in the decision to publish the results.

\section{References}

1. GBD 2016 Dementia Collaborators. Global, regional, and national burden of Alzheimer's disease and other dementias, 1990-2016: A systematic analysis for the Global Burden of Disease Study 2016. Lancet Neurol. 2019, 18, 88-106. [CrossRef]

2. Lang, L.; Clifford, A.; Wei, L.; Zhang, D.; Leung, D.; Augustine, G.; Danat, I.M.; Zhou, W.; Copeland, J.R.; Anstey, K.J.; et al. Prevalence and determinants of undetected dementia in the community: A systematic literature review and a meta-analysis. BMJ Open 2017, 7, e011146. [CrossRef] [PubMed]

3. Boustani, M.; Peterson, B.; Harris, R.; Lux, L.J.; Krasnov, C.; Sutton, S.F.; Hanson, L.; Lohr, K.N. Screening for Dementia. In U.S. Preventive Services Task Force Evidence Syntheses, Formerly Systematic Evidence Reviews; Agency for Healthcare Research and Quality: Rockville, MD, USA, 2003.

4. World Health Organization. Global Action Plan on the Public Health Response to Dementia 2017-2025; WHO: Geneva, Switzerland, 2017; pp. 14-16.

5. Nutbeam, D. Defining and measuring health literacy: What can we learn from literacy studies? Int. J. Public Health 2009, 54, 303-305. [CrossRef] [PubMed]

6. Sorensen, K.; Van den Broucke, S.; Fullam, J.; Doyle, G.; Pelikan, J.; Slonska, Z.; Brand, H. Consortium Health Literacy Project. Health literacy and public health: A systematic review and integration of definitions and models. BMC Public Health 2012, 12, 80. [CrossRef] [PubMed]

7. Kim, K.; Han, H.R. Potential links between health literacy and cervical cancer screening behaviors: A systematic review. Psychooncology 2016, 25, 122-130. [CrossRef] [PubMed]

8. Bostock, S.; Steptoe, A. Association between low functional health literacy and mortality in older adults: Longitudinal cohort study. BMJ 2012, 344, e1602. [CrossRef] [PubMed]

9. Chesser, A.K.; Keene, W.N.; Smothers, K.; Rogers, N. Health Literacy and Older Adults: A Systematic Review. Gerontol. Geriatr. Med. 2016, 2, 2333721416630492. [CrossRef] [PubMed] 
10. MacLeod, S.; Musich, S.; Gulyas, S.; Cheng, Y.; Tkatch, R.; Cempellin, D.; Bhattarai, G.R.; Hawkins, K.; Yeh, C.S. The impact of inadequate health literacy on patient satisfaction, healthcare utilization, and expenditures among older adults. Geriatr. Nurs. 2017, 38, 334-341. [CrossRef]

11. Owens, D.K.; Davidson, K.W.; Krist, A.H.; Barry, M.J.; Cabana, M.; Caughey, A.B.; Doubeni, C.A.; Epling, J.W.; Kubik, M.; Landefeld, C.S.; et al. Screening for cognitive impairment in older adults: US Preventive Services Task Force recommendation statement. JAMA 2020, 323, 757-763. [PubMed]

12. Chambers, L.W.; Sivananthan, S.; Brayne, C. Is dementia screening of apparently healthy individuals justified? Adv. Prev. Med. 2017, 9708413. [CrossRef]

13. Yu, S.Y.; Lee, T.J.; Jang, S.H.; Han, J.W.; Kim, T.H.; Kim, K.W. Cost-effectiveness of nationwide opportunistic screening program for dementia in South Korea. J. Alzheimers. Dis. 2015, 44, 195-204. [CrossRef]

14. Livingston, G.; Sommerlad, A.; Orgeta, V.; Costafreda, S.G.; Huntley, J.; Ames, D.; Ballard, C.; Banerjee, S.; Burns, A.; Cohen-Mansfield, J.; et al. Dementia prevention, intervention, and care. Lancet 2017, 390, 2673-2734. [CrossRef]

15. Sado, M.; Ninomiya, A.; Shikimoto, R.; Ikeda, B.; Baba, T.; Yoshimura, K.; Mimura, M. The estimated cost of dementia in Japan, the most aged society in the world. PLoS ONE 2018, 13, e0206508. [CrossRef]

16. Aihara, Y.; Maeda, K. Intention to undergo dementia screening in primary care settings among community-dwelling older people. Int. J. Geriatr. Psychiatry. 2020, 35, 1036-1042. [CrossRef]

17. Zhang, H.; Loi, S.M.; Zhou, S.; Zhao, M.; Lv, X.; Wang, J.; Wang, X.; Lautenschlager, N.; Yu, X.; Wang, H. Dementia literacy among community-dwelling older adults in urban China: A cross-sectional study. Front. Public Health 2017, 5, 124. [CrossRef]

18. Leung, A.Y.; Molassiotis, A.; Zhang, J.; Deng, R.; Liu, M.; Van, I.K.; Leong, C.S.U.; Leung, I.S.; Leung, D.Y.; Lin, X. Dementia Literacy in the Greater Bay Area, China: Identifying the At-Risk Population and the Preferred Types of Mass Media for Receiving Dementia Information. Int. J. Environ. Res. Public. Health 2020, 17, 2511. [CrossRef]

19. Boustani, M.; Perkins, A.J.; Fox, C.; Unverzagt, F.; Austrom, M.G.; Fultz, B.; Hui, S.; Callahan, C.M.; Hendrie, H.C. Who refuses the diagnostic assessment for dementia in primary care? Int. J. Geriatr. Psychiatry 2006, 21, 556-563. [CrossRef]

20. Awata, S.; Sugiyama, M.; Ito, K.; Ura, C.; Miyamae, F.; Sakuma, N.; Niikawa, H.; Okamura, T.; Inagaki, H.; Ijuin, M. Development of the dementia assessment sheet for community-based integrated care system. Geriatr. Gerontol. Int. 2016, 16 (Suppl. S1), 123-131.

21. Hoyl, M.T.; Alessi, C.A.; Harker, J.O.; Josephson, K.R.; Pietruszka, F.M.; Koelfgen, M.; Mervis, J.R.; Fitten, L.J.; Rubenstein, L.Z. Development and testing of a five-item version of the Geriatric Depression Scale. J. Am. Geriatr. Soc. 1999, 47, 873-878. [CrossRef] [PubMed]

22. Wada, Y.; Murata, C.; Hirai, H.; Kondo, N.; Kondo, K.; Ueda, K.; Ichida, N. Predictive validity of GDS5 using AGES project data. Kousei No Shihyou 2014, 61, 7-12. (In Japanese)

23. Kobayashi, L.C.; Wardle, J.; Wolf, M.S.; von Wagner, C. Aging and Functional Health Literacy: A Systematic Review and Meta-Analysis. J. Gerontol. B Psychol. Sci. Soc. Sci. 2016, 71, 445-457. [CrossRef]

24. Baker, D.W.; Gazmararian, J.A.; Sudano, J.; Patterson, M. The association between age and health literacy among elderly persons. J. Gerontol. B Psychol. Sci. Soc. Sci. 2000, 55, S368-S374. [CrossRef]

25. Koops van't Jagt, R.; de Winter, A.F.; Reijneveld, S.A.; Hoeks, J.C.; Jansen, C.J. Development of a communication intervention for older adults with limited health literacy: Photo stories to support doctor-patient communication. J. Health Commun. 2016, 21, 69-82. [CrossRef]

26. Uemura, K.; Yamada, M.; Okamot, H. Effects of active learning on health literacy and behavior in older adults: A randomized controlled trial. J. Am. Geriatr. Soc. 2018, 66, 1721-1729. [CrossRef]

27. Van Hoa, H.; Giang, H.T.; Vu, P.T.; Van Tuyen, D.; Khue, P.M. Factors Associated with Health Literacy among the Elderly People in Vietnam. Biomed. Res. Int. 2020, 2020, 3490635. [CrossRef] [PubMed]

28. Aihara, Y.; Minai, J. Barriers and catalysts of nutrition literacy among elderly Japanese people. Health Promot. Int. 2011, 26, 421-431. [CrossRef]

29. Carpenter, B.D.; Zoller, S.M.; Balsis, S.; Otilingam, P.G.; Gatz, M. Demographic and contextual factors related to knowledge about Alzheimer's disease. Am. J. Alzheimers. Dis. Other. Demen. 2011, 26, 121-126. [CrossRef]

30. Gaglio, B.; Glasgow, R.E.; Bull, S.S. Do patient preferences for health information vary by health literacy or numeracy? A qualitative assessment. J. Health Commun. 2012, 17 (Suppl. S3), 109-121. [CrossRef]

31. Boustani, M.; Watson, L.; Fultz, B.; Perkins, A.J.; Druckenbrod, R. Acceptance of dementia screening in continuous care retirement communities: A mailed survey. Int. J. Geriatr. Psychiatry 2003, 18, 780-786. [CrossRef] 
32. Low, L.F.; Anstey, K.J. Dementia literacy: Recognition and beliefs on dementia of the Australian public. Alzheimers. Dement. 2009, 5, 43-49. [CrossRef] [PubMed]

33. Martin, S.; Kelly, S.; Khan, A.; Cullum, S.; Dening, T.; Rait, G.; Fox, C.; Katona, C.; Cosco, T.; Brayne, C.; et al. Attitudes and preferences towards screening for dementia: A systematic review of the literature. BMC Geriatr. 2015, 15, 66. [CrossRef] [PubMed]

34. Martin, S.; Fleming, J.; Cullum, S.; Dening, T.; Rait, G.; Fox, C.; Katona, C.; Brayne, C.; Lafortune, L. Exploring attitudes and preferences for dementia screening in Britain: Contributions from carers and the general public. BMC Geriatr. 2015, 15, 110. [CrossRef]

35. Wilson, E.A.; Wolf, M.S.; Curtis, L.M.; Clayman, M.L.; Cameron, K.A.; Eigen, K.V.; Makoul, G. Literacy, cognitive ability, and the retention of health-related information about colorectal cancer screening. J. Health Commun. 2010, 15 (Suppl. S2), 116-125. [CrossRef] [PubMed]

36. Kobayashi, L.C.; Wardle, J.; von Wagner, C. Limited health literacy is a barrier to colorectal cancer screening in England: Evidence from the English Longitudinal Study of Ageing. Prev. Med. 2014, 61, 100-105. [CrossRef]

37. Krohne, K.; Slettebo, A.; Bergland, A. Cognitive screening tests as experienced by older hospitalised patients: A qualitative study. Scand. J. Caring Sci. 2011, 25, 679-687. [CrossRef]

38. Ashford, J.W.; Borson, S.; O’Hara, R.; Dash, P.; Frank, L.; Robert, P.; Shankle, W.R.; Tierney, M.C.; Brodaty, H.; Schmitt, F.A.; et al. Should older adults be screened for dementia? It is important to screen for evidence of dementia! Alzheimers. Dement. 2007, 3, 75-80. [CrossRef] [PubMed]

39. Choi, S.K.; Rose, I.D.; Friedman, D.B. How is literacy being defined and measred in dementia research? A scoping review. Gerontol. Geriatr. Med. 2018, 25, 4.

40. Bennett, D.A. How can I deal with missing data in my study? Aust. N. Z. J. Public Health 2001, 25, 464-469. [CrossRef]

Publisher's Note: MDPI stays neutral with regard to jurisdictional claims in published maps and institutional affiliations. 